\title{
DIAMOND GROWTH HISTORIES REVEALED BY CATHODOLUMINESCENCE AND CARBON ISOTOPE STUDIES.
}

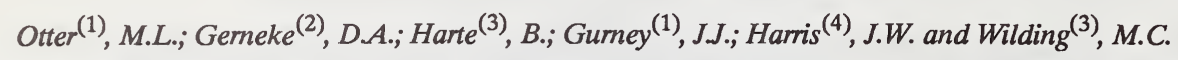

(1) Dept. of Geochemistry, University of Cape Town, Rondebosch, 7700 South Africa; (2) Electron Microscope Unit, University of Cape Town, Rondebosch, 7700 South Africa; (3) Dept. of Geology and Geophysics, University of Edinburgh, Edinburgh, EH9 3JW Scotland; (4) Dept. of Geology and Applied Geology, University of Glasgow, Glasgow G12 8QQ, Scotland.

The internal macro-structures of large (>2 carats) diamond crystals from four southern African kimberlites have been characterized using cathodoluminescence (CL) techniques, and the variation of carbon isotope composition within some of the crystals has been determined using the Edinburgh University/NERC ion microprobe.

Eclogitic and peridotitic inclusion suite diamonds from the Premier mine and peridotitic diamonds from Bultfontein, Finsch and Koffiefontein mines were investigated. The diamonds were halved along the cubic plane $\{100\}$ and polished. The CL characteristics of the polished faces were investigated using both Technosyn and Nuclide optical cathodoluminescence systems as well as a Cambridge S180 SEM with a CL detector. Most of the diamonds are zoned with respect to $\mathrm{CL}$. The zones presumably reflect variations in impurity content and distribution (e.g. nitrogen, see Davies, 1979), but the nature of the variation is unknown in detail.

The CL zoning indicates complicated histories of periodic growth with some phases of resorption. Alternations of cuboid and octahedral growth occur (Lang, 1974) in some crystals. In some cases, the cuboid growth orientation appears to result from simultaneous growth on two small octahedral faces. The three-dimensional manifestation of such growth would be an average growth surface roughly parallel to a rhombicdodecahedral face. Well defined CL zones sometimes truncate one another. Some truncations suggest resorption as shown by rounding-off of the corners of inner $\mathrm{CL}$ growth zones by an unrounded, continuous CL zone formed outside them. Other truncations do not involve rounding, but show sharply angular cross-cutting CL zones and may involve a change from cuboid to octahedral growth. This second type of truncation is partly related to differences in growth rate in different crystallographic directions, but resorption may be involved in some cases. 
Five diamonds, representing the peridotitic and/or eclogitic diamond groups at all four localities, were chosen for single-point carbon isotope analysis using the Cameca IMS $4 \mathrm{~F}$ Ion Microprobe at the University of Edinburgh. A primary $\mathrm{Cs}^{+}$ion beam, with a beam spot diameter of $\sim 5 \mu \mathrm{m}$, allowed variations of the carbon isotope composition within and between CL zones to be determined. The analyses are believed to be precise to $\pm 1 \%$ o $\delta^{13} \mathrm{C}$ (versus $\mathrm{PDB}$ ) based on replicate analyses of a synthetic diamond standard.

Significant (i.e. $>1 \%$ ) carbon isotope variation was found between the zones defined by CL in some of the crystals, but other crystals showing conspicuous CL zones appeared to be homogeneous throughout. Where carbon isotope variation occurred, as much as $4 \%$ change was found between zones, but no systematic variation in $\delta^{13} \mathrm{C}$ from centre to edge was observed. This is similar to the observations of wilding et al. (1990) and suggests that the diamonds did not crystallize in a single isotope fractionation sequence from a closed system carbon reservoir. Thus, open system behavior with variations in oxygen fugacity and/or source $\delta^{13} \mathrm{C}$ are indicated.

\section{REFERENCES}

Davies, G. (1979) Cathodoluminescence. In J.E. Field, Ed., Properties of Diamond, p. 165-181. Academic Press, London.

Lang, A.R. (1974) On growth sectorial dependence of defects in natural diamonds. Proceedings of the Royal society of London, A340, 233-248.

Wilding, M.C., Harte, B., and Harris, J.W. (1990) Carbon isotope variation in a zoned Bultfontein diamond, determined by S.I.M.S., Geological Society of Australia, Abstracts, 27, 112 . 